\title{
CI
}

I FELJCIDADE • TANTO MAR: ALTERNATIVAS À CARREIRA EXECUTIVA

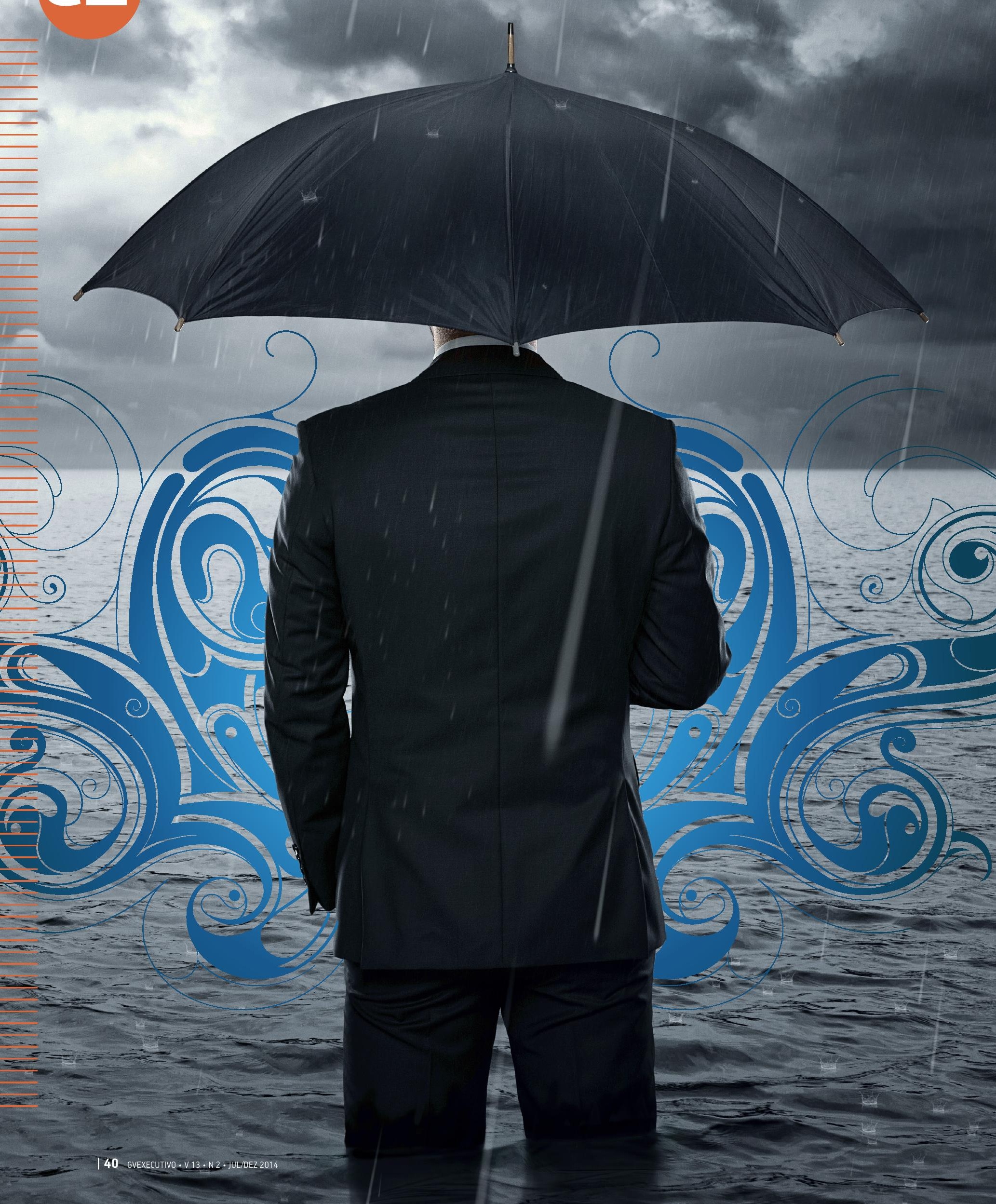




\section{TANTO MAR: \\ ALTERNATIVAS À \\ CARREIRA EXECUTIVA}

Depois de construir uma carreira executiva no setor privado, um profissional experiente explora novos territórios e investiga como, afinal, é a vida, e se há mesmo felicidade fora das corporações

| POR MARCIO OGLIARA

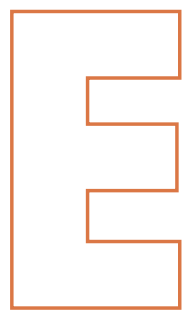

stou cursando o mestrado acadêmico em Administração de Empresas. É um mestrado sonhado, mas tardio. Tenho 54 anos e aproveitei minha dispensa na organização onde trabalhava para investir em uma nova carreira, depois de atuar anos em empresas. A vivência por muito tempo na área de Recursos Humanos (evito citar o número de anos ou décadas, suspeitando que isso não mais soe como um mérito ou algo positivo) e a observação de outros profissionais ajudaram para que eu me preparasse para esta aventura.

\section{MERGULHO NO ESCURO}

Ser dispensado de uma organização é sempre doloroso, por mais que isso possa ser previsto, pressentido ou até mesmo desejado. O rompimento dos vínculos e o medo de uma nódoa na imagem profissional ou pessoal pairam em todos os encontros, inclusive nos familiares e afetivos.

Foram meses para superar pensamentos sombrios e negativos, e isso contando com a ajuda de muitos amigos, além do suporte emocional de um trabalho de outplacement.

\section{SER DISPENSADO DE UMA ORGANIZAÇÃO É SEMPRE DOLOROSO. O ROMPIMENTO DOS VÍNCULOS E O MEDO DE UMA NÓDOA NA IMAGEM PROFISSIONAL OU PESSOAL PAIRAM EM TODOS OS ENCONTROS}

Outro aspecto relacionado à saída de uma organização são as mudanças inesperadas (e, suspeito, inconscientes) em algumas relações, porque você já não ocupa um determinado cargo, não tem aquele salário, não tem seu nome associado a alguma reluzente pessoa jurídica, e porque perdeu sua rotina diária. É uma época de muitas incertezas, reviravoltas e surpresas. Algumas agradáveis, outras francamente perturbadoras.

Quando eu estava empregado, sonhava com coisas que poderia fazer se não estivesse mais ali, preso. Viajar, escrever, lecionar... Tudo surgia como uma alternativa 


\section{HÁ ALTERNATIVAS REAIS E INTERESSANTES À VIDA CORPORATIVA. ELAS NECESSITAM DE PLANEJAMENTO, RESPONSABILIDADE E CORAGEM PARA SEREM EXPERIMENTADAS E VIABILIZADAS}

superior àquela que, em muitos momentos, parecia uma miserável e infeliz vida corporativa. Fora da empresa, a primeira coisa que descobri foi que o tempo havia se transformado misteriosamente: as longas horas na empresa pareciam simplesmente desaparecer em minha vida civil, e um dia inteiro poderia se passar sem que eu tivesse feito absolutamente nada de útil. Claro que, como qualquer cínico notaria, a mesma coisa poderia acontecer no trabalho. Mas haveria uma diferença marcante: a remuneração na empresa poderia magicamente apagar a perda do tempo, deixando apenas uma leve e passageira culpa em seu lugar.

\section{SONHADO VERSUS REAL}

Confesso que, depois de sair da empresa, consegui realizar apenas uma pequena parte dos meus sonhos. Viajar muito poderia ser alienante e me afastaria da família; escrever parecia doloroso e cansativo. A falta de rotina às vezes dava a sensação de abandono e inadequação. Eu tinha muito menos estresse e muito mais culpas do que antes. E descobri o óbvio: podemos nos imaginar fazendo muitas coisas, mas só temos noção da realidade a partir do momento em que efetivamente investimos naquilo de verdade. Estas outras atividades poderiam ser mais bem aproveitadas em outras circunstâncias? Sim! Com a experimentação antes de uma decisão definitiva.

Consegui uma vaga no mestrado de uma grande escola, na linha de Comportamento Organizacional, de alguma forma relacionada com o estudo de Recursos Humanos. Entrar no mundo acadêmico é uma experiência interessantíssima. Um ambiente que valoriza o conhecimento, a reflexão e a originalidade, e proporciona a construção de uma visão do humano e do social. Estimulante, controverso e, às vezes, para mim, equivocado, é como uma dimensão virtual do mundo real em busca de compreendê-lo. Pós-doutores, doutores e mestres - e seus respectivos gerúndios, categoria de que faço parte como mestrando - convivem em busca de descobertas, pesquisas, artigos, leituras, cursos e aulas. As valiosas comunicações, relacionamentos e colaborações internacionais entre as instituições dão um tom cosmopolita e global ao meio.

\section{DESCOBERTAS}

Posso dizer que foi um momento muito feliz para mim. Tinha um certo respeito e reconhecimento dos professores, pude me aproximar de meus colegas a despeito da diferença de idade (que é apenas uma entre as tantas distinções de origens, gêneros, interesses e visões de mundo) e participei de um ambiente instigante e divertido.

A maior surpresa nesse novo ambiente foi o meu reencontro com o marxismo. Depois de uma juventude socialista, minha visão de mundo havia mudado e eu estava certo de que ela estava alinhada com a modernidade e a academia. Comecei, inicialmente com grande incômodo, a participar de discussões em que o capitalismo, que eu via quase como um sinônimo de liberdade (entendo que a liberdade de empreender é uma das grandes liberdades individuais) era criticado por seus vícios. Interpretacionismo, pós-colonialismo, construcionismo, realismo crítico, pós-modernismo... A partir de qualquer perspectiva, o sistema estava sob questionamento. E nas fileiras críticas, gente do mais alto nível, com repertório suficiente para fazer com que eu me sentisse de volta ao Jardim II. Rebatia, inutilmente, devo dizer, com o que eu sabia e passei a colecionar pensadores como John Rawls, Sigmund Freud, Karen Legge e Zygmunt Bauman (estes dois últimos, críticos, mas muito lúcidos) tentando me situar naquela maré autodenominada progressista. Gosto de pensar que foi estimulante para todos. Ao mesmo tempo em que eu jogava água fria no quente e fácil consenso social, voltei a refletir com mais cuidado e revi algumas de minhas opiniões.

\section{PERSPECTIVAS}

Minha imaginada carreira acadêmica ainda está se iniciando. Aulas, palestras, monitorias, relacionamentos 


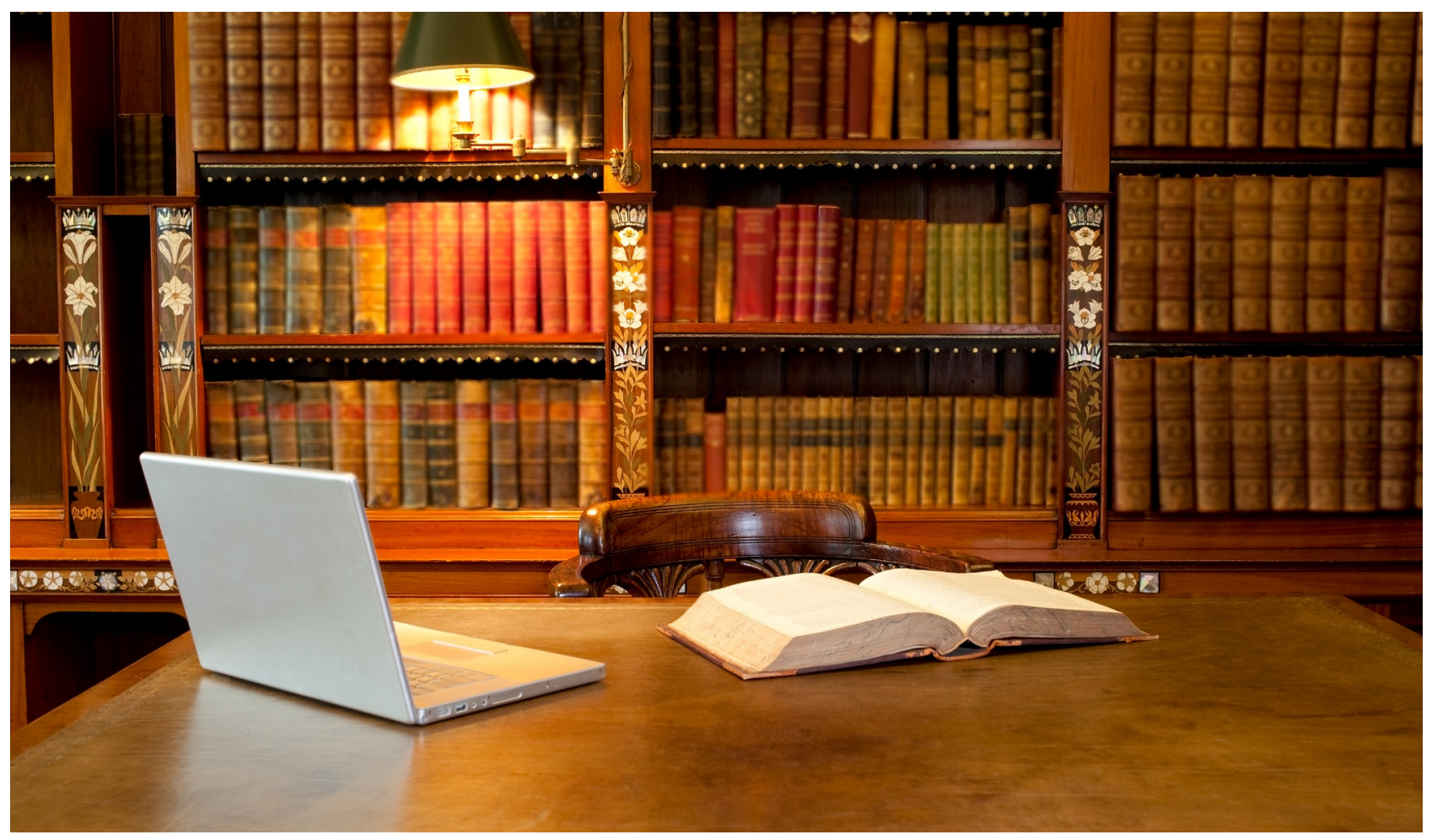

sendo construídos. Acreditava que poderia produzir conteúdo rapidamente, mas descobri que a escrita, neste caso, é rigorosa, o que é ótimo para a academia e penoso para o acadêmico. Além da clareza necessária, por causa das referências obrigatórias e do formato padronizado, ou você limita muito o assunto ou tende a se afundar num trabalho sem fim.

Estou empenhado em ler, discutir, aprender, pesquisar. A realidade brasileira, a evolução da ciência, a visão crítica, o estudo da ética e um aprofundamento do entendimento da gestão de recursos humanos estão entre os assuntos mais caros para mim. Meus amigos já cansaram de ouvir: falo as palavras ontologia e epistemologia e quero explicar o seu significado.

O tempo agora está dedicado ao gran finale do mestrado - a dissertação. Deve ser um trabalho de fôlego, uma contribuição (mais modesta que uma tese de doutorado e mais encorpada que um TCC da graduação) ao campo acadêmico escolhido. Conto com a imensa ajuda de uma orientadora, que consegue separar alguma coisa de valor no meio do que escrevo. A dissertação, assim como a tese, tem dois grandes momentos: o primeiro é a qualificação, em que uma banca aprova a proposta do trabalho; o segundo é a avaliação do trabalho final, também realizada por uma banca de professores. Os prazos, a questão fundamental da pergunta de pesquisa, a pesquisa em si, a escrita e a apresentação são motivos de desgaste e fragilidade emocional uma situação compartilhada por todos os mestrandos e doutorandos que conheço.

\section{TANTO MAR}

Tenho a conquista do conhecimento e do título de Mestre como um passo na busca de um ser humano e de um profissional melhor. E fica a certeza de que há alternativas reais e interessantes à vida corporativa, mesmo para os mais velhos. São alternativas que necessitam de planejamento, responsabilidade e coragem para serem experimentadas e viabilizadas. Embora ainda sem um porto seguro, trabalhando muito, às vezes incerto, às vezes encantado ao olhar para o horizonte, vivo interiormente a alegria de navegar, como nas viagens de Amir Klink.

MARCIO OGLIARA > Mestrando em Administração de Empresas na FGV-EAESP > mogliara@gmail.com 